\title{
Mean-median compromise method as an innovating voting rule in social choice theory
}

\author{
Ruffin-Benoît M. Ngoie ${ }^{1 *}$, Berthold Ulungu E.-L ${ }^{2,3}$ \\ ${ }^{1}$ Mathematics and Informatics Department, ISP/Mbanza-Ngungu, Democratic Republic of Congo \\ ${ }^{2}$ ISTA/Kinshasa, Democratic Republic of Congo \\ ${ }^{3}$ Laboratory, MATHRO,University of Mons, Belgium \\ *Corresponding author E-mail: benoitmpoy@hotmail.com
}

Copyright () 2015 Ruffin-Benoît M. Ngoie, Berthold Ulungu E.-L. This is an open access article distributed under the Creative Commons Attribution License, which permits unrestricted use, distribution, and reproduction in any medium, provided the original work is properly cited.

\begin{abstract}
This paper aims at presenting a new voting function which is obtained in Balinski-Laraki's framework and benefits mean and median advantages. The so-called Mean-Median Comprise Method (MMCM) has fulfilled criteria such as unanimity, neutrality, anonymity, monotonicity, and Arrow's independence of irrelevant alternatives. It also generalizes approval voting system.
\end{abstract}

Keywords: Aggregation, Approval Voting, Borda Majority Count, Majority Judgment, Social Choice Function.

\section{Introduction}

Election corresponds to the process by which individuals perform a choice which is expressed through vote, with aim of designating one or more individuals who will have the responsibility to occupy a political office (trade-union or administrative) [1].

Several models were proposed to fulfill this task but Arrow's one [2, 3] induced two paradoxes (Condorcet and Arrow's paradoxes) both insurmountable in theory and impossible to circumvent in practice. Social Choice Theory is, for this purpose, devoted to a reverse whatever the provided efforts because it is hardly able to solve the problem at its origin. We can advance a quite rational explanation to this constant impossibility confession and its corollary:

- Cause: the traditional model is inadequate because expressions of the allowed opinions to judges (ex-voters) are unsuited and insufficient

- $\quad$ Consequence: the theory which springs from is incoherent and contradictory.

Consequently, on the basis of this conviction, it is advisable to consider a new theory which pushes back the fixed limits of the arrovian framework. Michel Balinski and Rida Laraki undertook various works in this direction to propose a new framework not based on decision makers' individual preferences but on their evaluations $[4,5,6]$.

Thus, the Balinski-Larakian model requires from actors to make a judgment on each candidate in competition. In this meaning, it is more realistic to call actors "judges" (rather than voters or electors). Candidates are then "competitors". The Balinski-Laraki's model was adopted by several other researchers in Economics and Operations Research; its main characteristic is that judges do not need a numerical scale to evaluate candidates. An ordinal nominal scale is enough so that the common usual language can be used to evaluate candidates. By doing so, several methods were born; let us quote most representative:

- Approval voting: each judge approves or disapproves each candidate. The winner is the one who obtains most approvals.

- $\quad$ Evaluation voting: each judge allots a mark (or grade) to each candidate. The candidate who obtains the highest average or sum of marks is elected [7].

- Borda Majority Count (BMC): it is an extent of evaluation voting where a specific tie-breaking rule is used (see [8]). 
- Majority Judgment (MJ): each judge allots a grade (ordinal or cardinal) to each candidate. The winner is the one who obtains the highest median. This function uses two tie-breaking rules: majority-grade and majority-gauge (see [4], [5], and [6]).

- $\quad$ Mean-Median Compromise Method (MMCM): this method is obtained by hybridization of the BMC and MJ. Its tie-breaking rule returns values of a sequence that converge to the result of BMC before using tie-breaking rule suggested by Manzoor Ahmed Zahid (see [9], and [10]).

Interested reader can find more details in [11], [12] or [13]. It is suitable to note that Balinski-Laraki's MJ is a redefinition of Basset and Persky's Robust Voting [14] in the balinski-larakian framework.

The object of this paper is to isolate MMCM (see [9], and [10]), state and show its essential characteristics. For this purpose, the paper is organized as follows: section 2 outlines the so-called social choice function MMCM, section 3 enumerates some of its properties in the form of shown theorems. Lastly, section 4 is devoted to remarks and conclusion.

\section{Outlines of mean-median compromise method (MMCM)}

This section outlines the MMCM method proposed by Ngoie, Ulungu and Savadogo in [9], and [10]; there, didactic examples are also developped.

Definition 2.1 (Amplitude of a division) Let $N=\{1,2, \ldots, n\}$ be the set of $n$ judges, we call amplitude of a division the real number:

$\rho=\frac{\mathrm{n}+1}{2^{\mathrm{k}}}$

with $\mathrm{k}$ a whole number called "division degree".

Definition 2.2 (Intermedian grades) Let $a_{i}$ be a candidate or competitor with grade $g_{i 1}, g_{i 2}, \ldots, g_{i n}$ such that $g_{i 1} \geq g_{i 2} \geq$ $\cdots \geq g_{\text {in }}$. A grade $g_{i j}$ is called "intermedian" if and only if $\exists \mathrm{m} \in \mathrm{N}$ (with $1 \leq \mathrm{m} \leq 2^{\mathrm{k}}-1$ ) such that $[\rho . \mathrm{m}]=\mathrm{j}$ where $[\rho . \mathrm{m}]$ is the whole number that is nearest to $\rho . \mathrm{m}$ and $\rho$ the amplitude of division for a fixed division degree $\mathrm{k}$.

We note $\mathcal{M}_{\mathrm{k}}$ the set of non-redundant intermedian grades obtained from a division degree $\mathrm{k}$.

The so-defined $\mathcal{M}_{\mathrm{k}}$ is the set of data involved in the Olympic average ${ }^{1}$ calculation of points which are bounds (higher or lower) of $2^{\mathrm{k}}$ intervals obtained after division.

Definition 2.3 (Average Majority Compromise) Let $a_{i}$ be a candidate or competitor with grades $g_{i 1}, g_{i 2}, \ldots, g_{i n}$ where $\mathrm{g}_{\mathrm{i} 1} \geq \mathrm{g}_{\mathrm{i} 2} \geq \cdots \geq \mathrm{g}_{\mathrm{in}}$ and $\mathcal{M}_{\mathrm{k}}=\left\{\mathrm{g}_{\mathrm{i} 1}^{*}, \mathrm{~g}_{\mathrm{i} 2}^{*}, \ldots, \mathrm{g}_{\mathrm{ij}}^{*}\right\}$ the set of his or her intermedian grades obtained from division degreek. Then the "average majority compromise", or "average majority evaluation" or "average majority rank" $\mathrm{f}^{\mathrm{mm}}\left(\mathrm{a}_{\mathrm{i}}\right)$ is by definition:

$\mathrm{f}^{\mathrm{mm}}\left(\mathrm{a}_{\mathrm{i}}\right)=\frac{1}{\mathrm{j}} \sum_{\mathrm{m}=1}^{\mathrm{j}} \mathrm{g}_{\mathrm{im}}^{*}$

Example 2.1 If 5 judges assign grades $4,8,7,9,5$ to $\mathrm{a}_{\mathrm{i}}$. Suppose $\mathrm{k}=2, \rho=\frac{5+1}{2^{2}}=1.5$

When we arrange grades in descending order, we obtain: $9,8,7,5,4$

$\mathcal{M}_{2}=\left\{\mathrm{f}^{[1 \times 1.5]}, \mathrm{f}^{[2 \times 1.5]}, \mathrm{f}^{[3 \times 1.5]}\right\}=\left\{\mathrm{f}^{2}, \mathrm{f}^{3}, \mathrm{f}^{5}\right\}=\{8,7,4\}$

Thus $\mathrm{f}^{\mathrm{mm}}\left(\mathrm{a}_{\mathrm{i}}\right)=\frac{8+7+4}{3}=\frac{19}{3}=6.33$

And if 8 judges allot grades $9,7,3,6,5,4,5,8$ to $\mathrm{a}_{\mathrm{i}}$.

For $\mathrm{k}=3, \rho=\frac{8+1}{2^{3}}=1.125$

Classified grades in descending order are: 9, 8, 7, 6, 5, 5, 4, 3

$$
\begin{aligned}
\mathcal{M}_{3} & =\left\{f^{[1 \times 1.125]}, f^{[2 \times 1.125]}, f^{[3 \times 1.125]}, f^{[4 \times 1.125]}, f^{[5 \times 1.125]}, f^{[6 \times 1.125]}, f^{[7 \times 1.125]}\right\} \\
& =\left\{f^{[1.125]}, f^{[2.25]}, f^{[3.375]}, f^{[4.5]}, f^{[5.625]}, f^{[6.75]}, f^{[7.875]}\right\} \\
& =\left\{f^{1}, f^{2}, f^{3}, f^{5}, f^{6}, f^{7}, f^{8}\right\} \\
& =\{9,8,7,5,5,4,3\}
\end{aligned}
$$

Therefore $\mathrm{f}^{\mathrm{mm}}\left(\mathrm{a}_{\mathrm{i}}\right)=\frac{9+8+7+5+5+4+3}{7}=\frac{41}{7}=5.8$

\footnotetext{
${ }^{1}$ By Olympic average of $n$ numbers, we mean the arithmetic mean of these numbers when the two extreme values (largest and smallest) are excluded.
} 


\subsection{Tie-breaking}

When average majority grades of two candidates are different, the one with the higher average majority grade naturally ranks ahead of the other. Majority ranking $>_{m m}$ between two candidates evaluated by the same jury is determined by a repeated application of average majority ranking:

- $\quad$ start with $\mathrm{k}=2$

- $\quad$ if $\mathrm{f}_{\mathrm{k}}{ }^{\mathrm{mm}}$ (a) $>\mathrm{f}_{\mathrm{k}}{ }^{\mathrm{mm}}$ (b) then $\mathrm{a}>_{\mathrm{mm}} \mathrm{b}$

- $\quad$ if $\mathrm{f}_{\mathrm{k}}{ }^{\mathrm{mm}}(\mathrm{a})=\mathrm{f}_{\mathrm{k}}{ }^{\mathrm{mm}}$ (b) then the procedure is repeated for $\mathrm{k}+1$.

\subsection{Ranking candidates with MMCM}

Let us take the following example to illustrate this procedure:

Example 2.2 Let us suppose that a et $b$ are evaluated by a 7-voters jury:

\begin{tabular}{lcccccccc} 
a & $:$ & 85 & 73 & 78 & 90 & 69 & 70 & 71 \\
b & $:$ & 77 & 72 & 95 & 83 & 73 & 73 & 66 \\
\multicolumn{2}{l}{ The ordered } & profile is: & & & & & & \\
a & $:$ & 90 & 85 & 78 & 73 & 71 & 70 & 69 \\
b & $:$ & 95 & 83 & 77 & 73 & 73 & 72 & 66
\end{tabular}

$\rho=\frac{7+1}{2^{2}}=\frac{8}{4}=2$

$\mathcal{M}_{2} \stackrel{2^{2}}{=}\left\{f^{2}, f^{4}, f^{6}\right\}$

$\mathcal{M}_{2}(a)=\{85,73,70\}$ and $f_{2}{ }^{m m}(a)=\frac{85+73+70}{3}=76$

$\mathcal{M}_{2}(b)=\{83,73,72\}$ and $f_{2}{ }^{m m}(b)=\frac{83+73+72}{3}=76$

$f_{2}^{m m}(a)=f_{2}^{m m}(b)=76$. A tie-break occurs between $a$ and $b$. By definition, we repeat the procedure for $k=3$ and obtain:

$\rho=\frac{7+1}{2^{3}}=\frac{8}{8}=1$

$\mathcal{M}_{3}=\left\{f^{1}, f^{2}, f^{3}, f^{4}, f^{5}, f^{6}, f^{7}\right\}$

$\mathcal{M}_{3}(a)=\{90,85,78,73,71,70,69\}$ And $f_{3}^{m m}(a)=\frac{90+85+78+73+71+70+69}{7}=76.57$

$\mathcal{M}_{3}(b)=\{95,83,77,73,73,72,66\}$ And $f_{3}{ }^{m m}(b)=\frac{95+83+77+73+73+72+66}{7}=77$

$f_{3}^{m m}(b)=77>f_{3}^{m m}(a)=76.57$. Then $b>_{m m} a$.

In this example the average majority evaluation returns exactly the same result as the average. That is due to the fact that each candidate's intermedian grades set is equal her or his grade set.

Definition 2.4 (Maximum division index) Let $a_{i}$ be a candidate or competitor and $G_{i}=\left\{g_{i 1}, g_{i 2}, \ldots, g_{i n}\right\}$ set of $a_{i}$ 's grades with $g_{i 1} \geq g_{i 2} \geq \cdots \geq g_{i n}$ and $\mathcal{M}_{k}=\left\{g_{i 1}^{*}, g_{i 2}^{*}, \ldots, g_{i j}^{*}\right\}$ the set of her or his intermedian grades obtained with a division degree $k$. Then, the smallest whole number $k$ such that $G_{i}=\mathcal{M}_{k}$ is called "maximum division index" or "total division index". It is denoted $v$.

In example 2.2 stated above, the maximum division index is $v=3$.

\section{Properties of the MMCM}

First of all, let us notice that single member voting systems either with one or two rounds are used throughout the world for leaders' elections. Australia and Ireland cases which proceed to a complex method called transferable voting are likely to be considered as exceptions. To these exceptions, let us add Belgian case which uses a list-voting.

All voting functions here-mentioned are designed in arrovian framework. They suffer from inconsistencies such that it would not be right to affirm that they reflect the will of the people. For us to convince some, it would be enough to observe paradoxical results of French presidential elections of 1995, 2002 and 2007: in all these elections were observed Arrow's paradox (Independence of Irrelevant Alternatives), Condorcet-winner paradox and/or Condorcet-loser paradox (see e.g. $[15,16])$.

The so-called Social Choice Function MMCM was designed in order to avoid pitfalls of the previous voting functions. We show in this paper that most of paradoxes that affect these functions do not jeopardize the MMCM.

Definition 3.1 (Neutrality) Aggregating function $f$ is neutral if the winner between two or several candidates changes when all voters reverse their preferences (or evaluations).

Neutrality idea requires that if preferences radically change, election winner must change, too.

Theorem 3.1 : MMCM is neutral. 
Proof : Let us consider an electorate $N=\{1,2, \ldots, n\}$ of $n$ voters $(n \geq 2)$. If two candidates $x$ and $y$ are evaluated by these $n$ voters and their grades are respectively $X=\left\{g_{1 x}, g_{2 x}, \ldots, g_{n x}\right\}$ and $Y=\left\{g_{1 y}, g_{2 y}, \ldots, g_{n y}\right\}$ where $g_{i \alpha}$ indicates the grade allotted by voter $i$ to candidate $\alpha(i=1, \ldots, n ; \alpha=x$ or $y)$.

Suppose that $f^{m m}(X)>f^{m m}(Y)$. Therefore $x>_{m m} y$.

If each voter reverses her or his evaluation (i.e. $g_{i x}$ becomes $g_{i y}$ and vice versa $\forall i=1, \ldots, n$ ), the set of $x$ 's grades becomes $Y=\left\{g_{i y}\right\}_{i=1, \ldots, n}$ and $y$ 's one becomes $X=\left\{g_{i x}\right\}_{i=1, \ldots, n}$.

We then obtain $f^{m m}(X)>f^{m m}(Y) \Rightarrow y>_{m m} x$

Note: Neutrality theorem was already established for MJ and BMC [4, 5, 8]. A method obtained by hybridization of both above mentioned methods can only but fulfull this criterion.

Definition 3.2: (Anonymity) Aggregating function $\mathrm{f}$ is anonymous if the winner between two or several candidates does not change even when voters are permuted.

This definition indicates that if two voters exchange their ballot papers, the function must return the same result in both situations.

\section{Theorem 3.2 : MMCM is anomymous}

Proof: Let $x$ be a candidate whose set of grades allotted by $n$ voters $(n \geq 2)$ is $X=\left\{g_{1 x}, g_{2 x}, \ldots, g_{n x}\right\}$. If two voters $i$ and $j$ permute (i.e. $g_{i x}$ becomes $g_{j x}$ and vice versa whatever $\left.i, j=1, \ldots, n\right), X$ will not change.

Thus $f^{m m}(X)$ which is $x$ 's final evaluation by MMCM, will not change even if the voters were permuted. As $x$ is unspecified, this remains true for any candidate

Note: Even if this property seems to be weak, it is not fulfilled by districts-elections such as those implemented in the United States of America or proportional voting which is implemented in the Democratic Republic of Congo (DRC) for legislative elections and provincial ones.

Definition 3.3 : (Unanymity or Pareto-Consistency) Aggregating function $\mathrm{f}$ is unanimous if it always returns as the winning candidate between two or several candidates the one who is considered by all the voters to be the best.

This definition suggests that when all the voters prefer a candidate to all of her or his opponents, this candidate should not, in any case, whatever would be the profile, likely to be losing.

\section{Theorem 3.3 : MMCM is Pareto-consistent.}

Proof: Let $x$ and $y$ be two candidates with respective grades $G_{x}=\left\{g_{1 x}, g_{2 x}, \ldots, g_{n x}\right\}$ and $G_{y}=\left\{g_{1 y}, g_{2 y}, \ldots, g_{n y}\right\}$ such that $g_{i x}>g_{i y} \forall 1 \leq i \leq n$.

We will obtain for a division degree $k$ (with $k \geq 1$ ):

$\mathcal{M}_{k}(x)=\left\{g_{1 x}^{*}, g_{2 x}^{*}, \ldots, g_{m x}^{*}\right\}$ And $\mathcal{M}_{k}(y)=\left\{g_{1 y}^{*}, g_{2 y}^{*}, \ldots, g_{m y}^{*}\right\}$ (with $m=2^{k}-1$ ) where $\mathcal{M}_{k}(\alpha)$ indicates the intermedian set of candidate $\alpha$.

Since $g_{i x}>g_{i y} \forall 1 \leq i \leq n$, we have $g_{1 x}^{*}>g_{1 y}^{*} \forall 1 \leq i \leq m$ and thus,

$\frac{1}{m} \sum_{i=1}^{m} g_{1 x}^{*}>\frac{1}{m} \sum_{i=1}^{m} g_{1 y}^{*} \Rightarrow f^{m m}(x)>f^{m m}(y) \Rightarrow x>_{m m} y$

Definition 3.4 (Monotonicity) Aggregating function $\mathrm{f}$ is monotonic if it returns as winner a candidate with a profile $\mathrm{p}$ and keeps her or him as winner with a profile p' considering that in the last profile, at least one voter improved his grade for this candidate.

A candidate should not decrease in the final ranking if at least one judge re-examined her or him by allotting a higher grade.

\section{Theorem 3.4 : MMCM is monotonic.}

Proof: Let $x$ and $y$ be two candidates with respective $G_{x}=\left\{g_{1 x}, g_{2 x}, \ldots, g_{n x}\right\}$ and $G_{y}=\left\{g_{1 y}, g_{2 y}, \ldots, g_{n y}\right\}$ such that $f^{m m}(x)>f^{m m}(y)$ (i.e. $\left.x>_{m m} y\right)$.

Suppose that voter $i$ having previously allotted grade $g_{i x}$ to $x$ re-evaluated her or him by allotting a grade $g_{i x}^{\prime}$ such that $g_{i x}^{\prime}>g_{i x}$ ceteris paribus. Three cases are then possible:

- Grade $g_{i x}^{\prime}$ does not amend the overall constitution of intermedian grades $\mathcal{M}_{k}(x) . f^{m m}(x)$ Remains the same and $f^{m m}(x)>f^{m m}(y)$.

- $\quad$ Grade $g_{i x}^{\prime}$ is an intermedian (i.e. voter $i$ is pivotal) and $f_{i}^{m m}(x)$ which is $x$ 's final evaluation by MMCM after taking into account the preference amendment of voter $i$.

Thus $\mathrm{f}_{\mathrm{i}}^{\mathrm{mm}}(\mathrm{x})>\mathrm{f}^{\mathrm{mm}}(\mathrm{x})>\mathrm{f}^{\mathrm{mm}}(\mathrm{y}) \Rightarrow \mathrm{f}_{\mathrm{i}}^{\mathrm{mm}}(\mathrm{x})>\mathrm{f}^{\mathrm{mm}}(\mathrm{y})$

- Grade $\mathrm{g}_{\mathrm{ix}}^{\prime}$ is not intermedian but amends the overall constitution of intermedian grades $\mathcal{M}_{\mathrm{k}}(\mathrm{x})$. In this case, an intermedian grade is replaced by another by shifting a row on the left. Let $\mathrm{g}_{\mathrm{jx}}^{*}$ be the replaced grade. This grade is replaced by $g_{(j-1) x}^{*}$. However $g_{(j-1) x}^{*}>g_{j x}^{*}$ (grades being ordered in a decreasing order before evaluating $\mathrm{f}^{\mathrm{mm}}$ ). We then have $\mathrm{f}_{\mathrm{i}}^{\mathrm{mm}}(\mathrm{x})>\mathrm{f}^{\mathrm{mm}}(\mathrm{x})>\mathrm{f}^{\mathrm{mm}}(\mathrm{y}) \Rightarrow \mathrm{f}_{\mathrm{i}}^{\mathrm{mm}}(\mathrm{x})>\mathrm{f}^{\mathrm{mm}}(\mathrm{y})$. 
Definition 3.5 (Independence of Irrelevant Alternatives) Aggregating function $\mathrm{f}$ is independent from irrelevant alternatives if it establishes that ranking between two candidates depends only on voters' preferences (or evaluations) on these candidates. The addition or withdrawal of another candidate does not have, in any case, to modify this ranking.

The non-observance of this criterion is known as Arrow's paradox. When an aggregating function does not fulfill this criterion, it is regarded as vulnerable to the Arrow's paradox. This paradox is very frequent in elections all over the world. It was observed in particular in the United States of America in 2000 (candidature of Ralph Nader supporting Georges Bush election against Albert Gore), in 2002 French presidential elections (candidature of Jean-Pierre Chevenement hindering Lionel Jospin to reach the second round) and 2007 french presidential elections (if there were no socialist candidature or UMP (Union pour la Majorité Présidentielle) candidacy, Bayrou would be elected President of the Republic - according to all surveys, he was the Condorcet-winner). In DRC, many surveys indicated that a candidate from the opposition would probably win the 2011 presidential election against Presidential Majority (MP: Majorité Présidentielle) candidate if there were not multiplicity of candidature from the opposition.

\section{Theorem 3.5 : MMCM is independent from irrelevant alternatives.}

Proof: Evaluations by voters are cast on the basis of candidates' performance independently from each other. Thus, if any voter $\mathrm{i}$ allot a score or grade $\mathrm{g}_{\mathrm{ix}}$ to candidate $\mathrm{x}$ and $\mathrm{g}_{\mathrm{iy}}$ to another candidate $\mathrm{y}$ such that $\mathrm{g}_{\mathrm{ix}} \geq \mathrm{g}_{\mathrm{iy}}$, whatever grade $\mathrm{g}_{\mathrm{iz}}$ she or he allots in addition to candidate $\mathrm{z}$, therefore ordrer $\mathrm{g}_{\mathrm{ix}} \geq \mathrm{g}_{\mathrm{iy}}$ will never be modified

In a survey carried out by Jean-François Laslier [17], experts in Social Choice Theory were invited to make a statement on 18 voting systems. These voting systems were regarded as candidates for an election of approval voting kind. The winner with this experiment was of course the approval voting (AV) with $68.18 \%$ of voters (specialists) having approved of it. However, the approval voting is a specific case of the evaluation voting (or to some extent Range Voting) and of the Majority Judgment (cf. [18]).

In this Laslier's experiment, Majority Judgment is ranked eighth with $22.73 \%$ of voters having approved it and evaluation voting ranks eleventh with $9.09 \%$ of voters having approved it. We show in this article that approval voting is also a specific case of the MMCM.

Theorem 3.6 : MMCM is equivalent to approval voting as allowed scores are 1 or 0.

By stating this theorem we want to show that result obtained by MMCM is the same as approval voting one if the only authorized scores are 0 (to code "disapproved") and 1 (to code "approved"). As the Laslier's experiment [17] shows it, that does not guarantee to us its acceptance on behalf of all the partisans of the approval voting. Thus, this theorem remains only one contribution or an argument to defend the MMCM.

Proof: If the only allowed scores are 0 and 1 , for all $x, y$ two candidates with respective scores $G_{x}=\left\{g_{1 x}, g_{2 x}, \ldots, g_{n x}\right\}$ and $\mathrm{G}_{\mathrm{y}}=\left\{\mathrm{g}_{1 \mathrm{y}}, \mathrm{g}_{2 \mathrm{y}}, \ldots, \mathrm{g}_{\mathrm{ny}}\right\}$ where $\mathrm{g}_{\mathrm{ij}}=0$ or $1 \forall \mathrm{i}=1, \ldots, \mathrm{n}, \forall \mathrm{j}=\mathrm{x}$ or $\mathrm{y}$.

According to approval voting, $x>y$ if $G_{x}$ has more " 1 " (or approvals) than $G_{y}$. Let us suppose that this result is not corroborated by MMCM i.e. $G_{x}$ has more " 1 " than $G_{y}$ and $f^{m m}(x)<f^{m m}(y)$. This means that $\exists k \geq 1$ such that $\mathcal{M}_{k}(x)$ includes less " 1 " than $\mathcal{M}_{k}(y)$. This is absurd according to [9], $\mathcal{M}_{k}(x)$ converges to $G_{x}$ and $\mathcal{M}_{k}(y)$ to $G_{y}$ when $k$ tends to $v$ (maximum division index) (cf. Theorem 5.2 in [9]). Since $G_{x}$ has more "1" than $G_{y}, \mathcal{M}_{k}(x)$ should include at least as many " 1 " as $\mathcal{M}_{k}(y)$. Therefore we must have $f^{m m}(x)>f^{m m}(y) \Longrightarrow x>_{m m} y$.

\section{MMCM versus most valuable Social Choice Functions}

It would be better to introduce here a table comparing representative social choice functions over some properties. At least, MMCM is compared to BMC and MJ. In table 1 below, "1" in a box means that the social choice function on the associate column fulfills criterion on the associate line, otherwise we mark down " 0 ".

Table 1: Comparing MMCM to most valuable social choice functions

\begin{tabular}{|c|c|c|c|c|c|}
\hline Properties & МMCM & MJ & BMC & $\mathbf{A V}$ & Plurality Voting \\
\hline Neutrality & 1 & 1 & 1 & 1 & 1 \\
\hline Anonymity & 1 & 1 & 1 & 1 & 1 \\
\hline Unanimity & 1 & 1 & 1 & 1 & 1 \\
\hline Monotonicity & 1 & 1 & 1 & 1 & 0 \\
\hline Independence of Irrelevant Alternative & 1 & 1 & 1 & 1 & 0 \\
\hline Generalizing AV & 1 & 1 & 1 & 1 & 0 \\
\hline High Expressivity from Voter & 1 & 1 & 1 & 0 & 0 \\
\hline Robustness & 1 & 1 & 0 & 0 & 0 \\
\hline Majority-Tyranny-Proofness & 1 & 0 & 1 & 0 & 0 \\
\hline
\end{tabular}


Beyond above-mentioned criteria, MMCM still fulfills other fair criteria such as honesty of voter (betraying one's favorite candidate does not pay), allowance of having no opinion vote, immunity to candidate cloning, etc.

\section{Concluding remarks}

In this paper, we outlined a new voting system obtained by combination of Borda Majority Count (see [8]) and Majority Judgment (see $[4,5,6]$ ). The principle of this new method consists in dividing the ordered list of grades in $m$ equal parts and retaining only bounds of internal parts. Average of selected grades or marks (intermedians) is the returned value. It consists in increasing the number of parts in the list of grades [9]. The suggested tie-breaking rule differs as well from the BMC as the MJ.

It was also shown that MMCM fulfills a number of desirable properties which are not available for common voting systems. MMCM thus fits incontestably in the list of voting functions which are simultaneously monotonic, unanimous, neutral and independent from irrelevant alternatives.

MMCM still fulfills more other criteria which were not referred to in this article. For example, it is more likely strategyproof than BMC or any other form of voting based on the summation or the average of grades.

Indeed, it generalizes the approval voting, one of the most valued functions according to many specialists in Social Choice Theory (see [19, 20, 21]).

Acknowledgments: The authors are grateful to Jean-François Laslier (from CNRS, France) for constructive discussions about Robust Voting and MJ. They are also grateful to anonymous referee(s) for invaluable and useful suggestions.

\section{References}

[1] Nicolas Jean. Environnement politique et élections : Une étude des déterminants du vote appliquée aux élections municipales françaises. $\mathrm{PhD}$ thesis, Université des Sciences et Technologies de Lille, 2012.

[2] Kenneth J. Arrow. Social choice and individual values, Yale University Press, 1951.

[3] Kenneth J. Arrow. Social choice and individual values, Yale University Press, 1963.

[4] Michel Balinski and Rida Laraki. A theory of measuring, electing and ranking. Proceedings of the National Academy of Sciences of the United States of America, pages 8720-8725, 2007.

[5] Michel Balinski and Rida Laraki. Majority Judgment: measuring, ranking and electing. MIT Press, 2010.

[6] Michel Balinski and Rida Laraki. Jugement majoritaire vs vote majoritaire. Cahier 2012-37, CNRS, 2012.

[7] José Carlos R. Alcantud and Annick Laruelle. Dis\& approval voting: a characterization. Social Choice and Welfare, 43(1):1-10, 2014. http://dx.doi.org/10.1007/s00355-013-0766-7.

[8] Manzoor Ahmed Zahid. A new framework for elections. PhD thesis, Tilburg University, 2012.

[9] Ruffin-Benoît M. Ngoie, Zoïnabo Savadogo, and Berthold E.-L. Ulungu. Median and average as tools for measuring, electing and ranking: new prospects. Fundamental Journal of Mathematics and Mathematical Sciences, 1(1):9-30, 2014.

[10] Ruffin-Benoit M. Ngoie, Zoïnabo Savadogo, and Berthold E.-L. Ulungu. New Prospects in Social Choice Theory: Median and average as tools for measuring, electing and ranking. Adv. Stud. Contemp. Math., 25(1): 19-38, 2015.

[11] Edurne Falco and José Luis Garcia-Lapresta. A distance-based extension of the majority judgement voting system. In Acta Universitatis Belii, Mathematics 18, pages 17-27, 2011.

[12] Edurne Falco, José Luis Garcia-Lapresta, and Llorenç Rosello. Allowing voters to be imprecise: à proposal using multiple linguistic terms. Information Sciences, 2013.

[13] Edurne Falco, José Luis Garcia-Lapresta, and Llorenç Rosello. Aggregating imprecise linguistic expressions. In P. Guo and W. Pedrycz, editors, Human-Centric Decision Making Models for Social Sciences. 2014. http://dx.doi.org/10.1007/978-3-642-39307-5 5.

[14] Gilbert W. Basset and Joseph Persky. Robust voting. Public Choice, 99:299-310, 1999. http://dx.doi.org/10.1023/A:1018324807861.

[15] Sylvain Durand. Sur quelques paradoxes en Théorie du Choix Social et en décision multicritère. PhD thesis, Université Joseph FourierGrenoble 1, 2000.

[16] Dan S. Felsenthal. Electoral Systems. Paradoxes, Assumptions, and Procedures, chapter 3: Review of Paradoxes Afflicting Procedures for Electing a Single Candidate. Springer-Verlag, Berlin Heidelberg, 2012.

[17] Jean-François Laslier. Electoral Systems, chapter 13: And the loser is... Plurality Voting. Springer-Verlag, Berlin Heilderberg, 2012.

[18] Warren D. Smith. Range voting. http://rangevoting.org/RangeVoting.html, 2012.

[19] Antoinette Baujard and Herrade Igersheim. Expérimentation du vote par note et du vote par approbation le 22 avril 2007. Premiers résultats. Revue économique, 60(1):189-201, 2009.

[20] Antoinette Baujard, Frédéric Gavrel, Herrade Igersheim, Jean-François Laslier, and Isabelle Lebon. Who's favored by evaluative voting ? an experiment conducted during the 2012 french presidentiel election. Cahier 2013-05, CNRS, 2013.

[21] Jean-François Laslier and Karine Van der Straeten. Une expérience de vote par assentiment. Revue française de science politique, 54(1):99130, 2004. http://dx.doi.org/10.3917/rfsp.541.0099. 